\title{
Mapping Urban Heat Vulnerability of Extreme Heat in Hangzhou via Comparing Two Approaches
}

\author{
Xue Liu, ${ }^{1}$ Wenze Yue $\mathbb{D}^{1},{ }^{1}$ Xuchao Yang, ${ }^{2}$ Kejia Hu, ${ }^{2}$ Wei Zhang, ${ }^{3}$ and Muyi Huang $\mathbb{D D}^{4}$ \\ ${ }^{1}$ Department of Land Management, Zhejiang University, Hangzhou 310058, China \\ ${ }^{2}$ College of Ocean, Zhejiang University, Zhoushan 316021, China \\ ${ }^{3}$ Shanghai Institute of Geological Survey, Shanghai 200072, China \\ ${ }^{4}$ Department of Environmental Engineering, Anhui Jianzhu University, Hefei 230601, China \\ Correspondence should be addressed to Wenze Yue; wzyue@zju.edu.cn and Muyi Huang; huangyang78@163.com
}

Received 3 March 2020; Revised 20 May 2020; Accepted 20 May 2020; Published 23 June 2020

Academic Editor: Lingzhong Guo

Copyright (c) 2020 Xue Liu et al. This is an open access article distributed under the Creative Commons Attribution License, which permits unrestricted use, distribution, and reproduction in any medium, provided the original work is properly cited.

\begin{abstract}
Extreme heat is the leading cause of heat-related mortality around the world. Extracting heat vulnerability information from the urban complexity system is crucial for urban health studies. Using heat vulnerability index (HVI) is the most common approach for urban planners to locate the places with high vulnerability for intervention and protection. Previous studies have demonstrated that HVI can play a vital role in determining which areas are at risk of heat-related deaths. Both equal weight approach (EWA) and principal component analysis (PCA) are the conventional methods to aggregate indicators to HVI. However, seldom studies have compared the differences between these two approaches in estimating HVI. In this paper, we evaluated the HVIs in Hangzhou in 2013, employing EWA and PCA, and assessed the accuracies of these two HVIs by using heat-related deaths. Our results show that both HVI maps showed that areas with high vulnerability are located in the central area while those with low vulnerability are located in the suburban area. The comparison between $\mathrm{HVI}_{\mathrm{EWA}}$ and $\mathrm{HVI}_{\mathrm{PCA}}$ shows significantly different spatial distributions, which is caused by the various weight factors in EWA and PCA. The relationship between $\mathrm{HVI}_{\mathrm{EWA}}$ and heat-related deaths performs better than the relationship between $\mathrm{HVI}_{\mathrm{PCA}}$ and deaths, implying EWA could be a better method to evaluate heat vulnerability than PCA. The $\mathrm{HVI}_{\mathrm{EWA}}$ can provide a spatial distribution of heat vulnerability at intracity to direct heat adaptation and emergency capacity planning.
\end{abstract}

\section{Introduction}

The impacts of extreme heat are a public health concern [1-3]. Extreme heat events can cause heat stress when the human body is not able to effectively dissipate heat, and the body temperature rises [4]. In the context of global warming, extreme heat is thought to be the leading cause of weatherrelated morbidity and mortality [5-7]. For instance, during the 1995 heat waves in the United States, over 700 people died as a result of extreme heat in Chicago and Illinois alone $[8,9]$. Heat waves in the summer of 2003 killed more than 70,000 people in Europe [10]. More than 15,000 people died in heat waves in Moscow and parts of western Russia in July 2010 [11]. The adverse health impacts of extreme heat are far more than the heat waves that happened in the past. There is growing evidence that the frequency, duration, and intensity of heat waves are likely to increase in the future [2], especially in urban areas [12]. Meanwhile, urban centers were home to over $50 \%$ of the World's population in 2010, and approximately $60 \%$ of the projected global population of 8.2 billion will live in cities by $2030[13,14]$. Increasing population accompanied by an intense thermal environment implies more intracity areas could be vulnerable to heatrelated health risks $[7,15]$.

So far, growing concerns for the health of current and future populations have motivated scholars and policymakers to assess the heat-health risks and develop relevant mitigation and adaptation strategies [16, 17]. Previous studies on mapping urban vulnerability have established a heat-related study framework $[18,19]$, explored the urban 
heat island (UHI)-mortality associations $[7,15,20]$, identified vulnerable subgroups $[9,21,22]$, and mapped heat vulnerability risks [23-26]. Different scientific communities apply different definitions for connecting an adverse effect with risks [27]. One simple tool is to use heat vulnerability index, which can aggregate many heat vulnerability indicators into a single score to represent the place with high heat risks. Considering the different methods to aggregate heat vulnerability, previous studies can be divided into two groups. In the first group, the weights of indicator are subjectively assigned (e.g., the weights of indicators are equal) $[23,28,29]$. In the second group, the weights of indicators are objectively assigned based on the statistical analysis [30-32]. Principal component analysis (PCA) is the most common method in relative studies. There is a study focusing on the comparison of two methods [33]. However, the lack of corresponding validation data prevents us from knowing which method is more appropriate.

Furthermore, most studies mainly focused on major cities in developed countries, such as Chicago [7], Toronto [25], Birmingham and [19], Rennes [18]. Besides, heathealth risk assessments at the regional scale also have been conducted, such as the Washington Metropolitan Area [28], Georgia [16], and South Quebec [26]. While the cause and progression of the heat risk in individual cities or regions are relatively well understood, many important questions remain concerning how the risk distributes and how to mitigate in the intracity [27]. Meanwhile, the distribution of heat-health risk in developing countries is rarely well-known [29]. A few relevant studies in China barely estimated health risk at the province or municipality scale disregarding urban versus rural environments [29, 34, 35] although part of the risk study in Beijing has mentioned comparison of the borderland area and urban area [35].

The relative previous UHI studies in the city of Hangzhou can be categorized into three groups according to their contents. In the first group, studies have focused on the assessment of UHI intensity and spatiotemporal pattern of UHI with a high level of detail, which have shown that the urban core has the higher UHI intensity while the suburb area has the lower UHI intensity [36, 37]. In the second group, cross-sectional studies have attempted to understand the relationship between the UHI and land cover patterns [38], land use type [39], and urban structure [40]. In the third group, simulation models, such as weather research and forecasting (WRF) and ENVI-met, have been utilized to predict and mitigate the future UHI intensity [41, 42]. However, there is a seldom study about the impacts of UHI on human health in Hangzhou, which has been proved that UHI is responsible for adverse human health in Shanghai [43]. One can argue that the studies examining UHI distribution are similar to the studies of investigating heat vulnerability. However, the lack of socioeconomic components in most UHI studies hinders further research on heat vulnerability since UHI only represents the heat hazard, and socioeconomic components represent the ability to cope with the heat hazard $[15,18]$. It is thought that incorporating the UHI with socioeconomic components may yield a more robust heat vulnerability than the socioeconomic components alone [44].

Therefore, mapping health risk distribution at intracity fosters the understanding of factors causing heat vulnerability and provides insights into urban vulnerability mitigation and management. Taking Hangzhou intracity area as an example, this study aimed to explore that (1) what is the spatial pattern of LST in Hangzhou, China? (2) what are the spatial patterns of HVIs using two different methods? Also, (3) which method can better be used to evaluate the heat vulnerability? The remainder of this paper is as follows: in Section 2, we illustrate the study area, data sources, and methods. The results are presented in Section 3, followed by discussion (Section 4) and conclusions (Section 5).

\section{Materials and Methods}

2.1. Study Area. Hangzhou, the capital of Zhejiang Province, is located in the Yangtze Delta of east China (Figure 1). Hangzhou has an area of $3068 \mathrm{~km}^{2}$ and a population of 8.89 million in 2014. It has experienced rapid urban expansion and population growth in recent years, with an urban population ratio of $62.1 \%$ in 2005 and $70.0 \%$ in 2010 [45, 46]. Hangzhou's climate is a typical subtropical monsoon climate with hot and humid summers: the mean daily temperature in the summer ranged from $24.3^{\circ} \mathrm{C}$ to $28.4^{\circ} \mathrm{C}$ between 1971 and 2000 (http://www.weather.com.cn/). As one of China's emerging "four ovens," Hangzhou experienced an extremely hot summer during the 2013 heatwave, which includes a total of 47 days with a maximum temperature above $35^{\circ} \mathrm{C}$. Besides, the threat of extreme heat events is likely to increase due to the combined effects of global warming and rapid urbanization in the future.

Based on our goals, the study area focused on the intracity composes of six central districts (Figure 1). We selected the subdistrict as the analytical unit, which is the smallest territorial unit defined to take a population census and the smallest administrative division. Therefore, subdistrict is the level at which most of the local urban planning and management decisions are designed and implemented. It is appropriate to use the subdistrict as the spatial unit to characterize the health risk. A total of 49 subdistricts were selected (Figure 1). The size of selected subdistricts ranged from 1.11 to $74.66 \mathrm{~km}^{2}$, with the mean and standard deviation of 13.39 and $17.75 \mathrm{~km}^{2}$.

\subsection{Data Preprocessing}

\subsubsection{Data Sources}

(1) Satellite Data. Conventional LST calculations require software installation (e.g., ENVI and ERDAS) and raw satellite data downloads, which could be extremely timeconsuming [47-49]. Google Earth Engine (GEE) provides an online platform with access to a vast catalog of satellite imagery and planetary-scale analysis capabilities; it is now possible to acquire satellite data information that does not require any preprocessing or installation of software [49]. The main source of data in this study concerns Landsat 8 


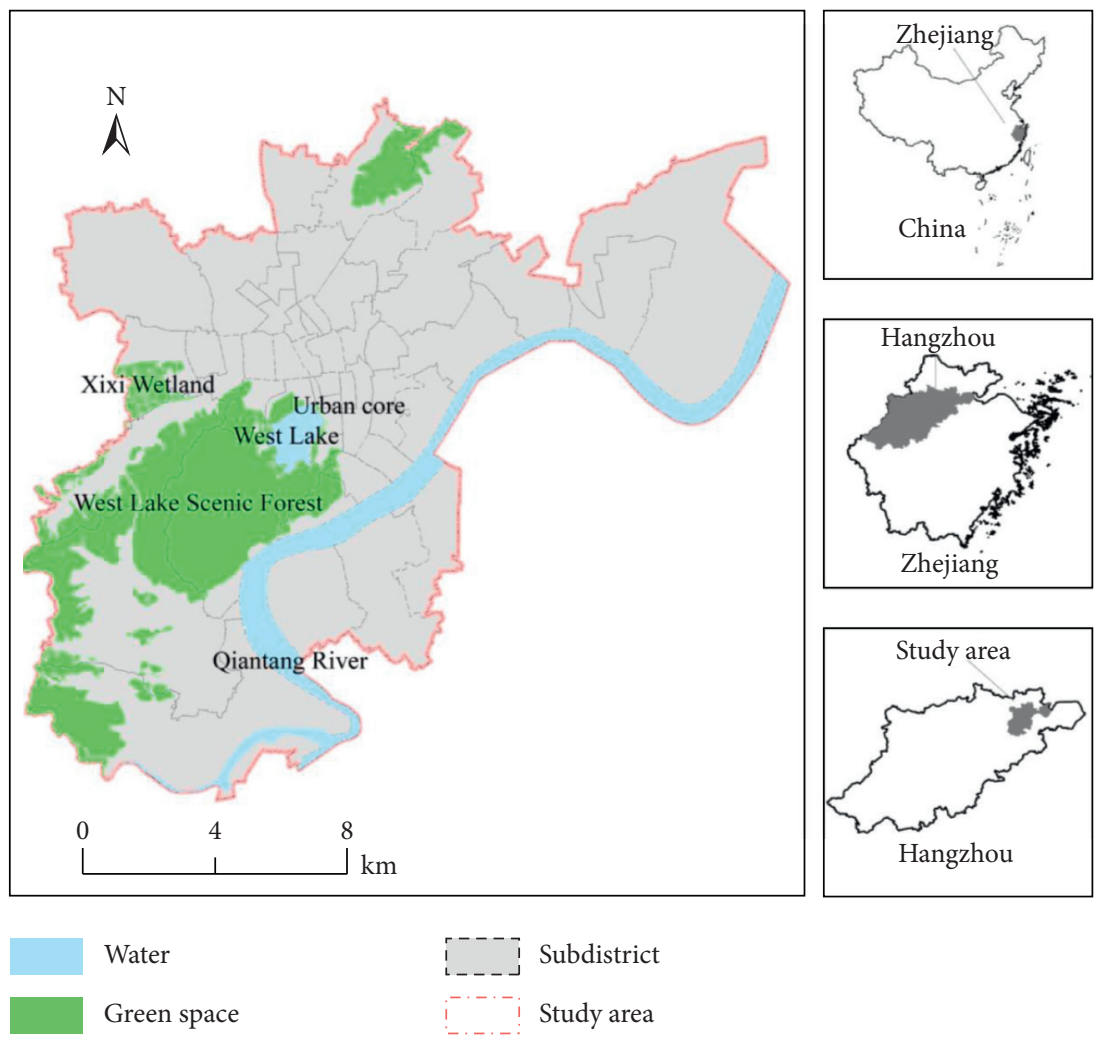

Figure 1: The locations of study area.

acquisitions, provided by the United States Geological Survey (USGS) and included in the GEE data catalog, which is the same as previous studies $[50,51]$. Landsat 8 surface reflectance products (GEE product ID: LANDSAT/LC8/ C01/T1_SR) from June to August 2013 that covers Hangzhou were used in this study (Table 1). Although the spatial resolution of the thermal infrared band of Landsat 8 is $100 \mathrm{~m}$, all the products are resampled by the USGS to $30 \mathrm{~m}$ by using a cubic convolution resampling method [49].

(2) Demographic and Socioeconomic Data. Total population, the population of the elderly (aged 65+) at the subdistrict level (49 units in total), the population of the elderly that live alone over 60, the population less than high school education, unhealthy population over 60 (unhealthy seniors), and illiteracy population over 15 at the subdistrict level were collected from China's Sixth (2010) National Census (http:// www.stats.gov.cn/). Disposable income data were obtained from the Hangzhou Bureau of Statistics (Hangzhou Statistical Yearbook 2014).

(3) Cooling Facilities Data. Public access to cooling facilities (e.g., supermarkets, shopping plazas, and libraries) could provide emergency cooling shelters to neighboring residents without affordable air conditioning [25]. Locations of these facilities were derived from Hangzhou's essential geographic elements in the Baidu Map Database (http://www.baidu. $\mathrm{com} /$ ).
(4) Green Space Data. According to the previous studies, green space can provide a mitigation effect of the heat environment $[24,52]$. Lack of green space can be used as a higher heat exposure risk. Deciduous forest, evergreen forest, mixed forest, shrub, grassland, parks, and wetlands were collected as the green space from Hangzhou Land Cover Database in 2013. The reciprocal of the proportion of green space in each subdistrict was defined as the lack of green space to satisfy the larger numbers implying a higher vulnerability.

(5) Heat-Related Death Data. An epidemiological study revealed that extreme heat events were closely associated with increased morbidity or mortality, such as cardiovascular and respiratory mortality [53]. Mainly, the data of heat-related morbidity or mortality are used to represent the health risk [54]. In this study, we used the death data to validate our heat risk assessment, which reported for urban areas in Hangzhou during the 2013 summer (June-August), provided by Zhejiang Centre for Disease Control and Prevention. In specific, we considered deaths combined deaths, under the International Classification of Diseases (ICD), caused by cardiovascular diseases (ICD-10 codes, I00-I99), respiratory diseases (ICD10, J00-J99), heat stroke (ICD10, X30), dehydration (ICD10, E86), and hyperpyrexia (ICD10, R50.9) were related to heatwaves [34]. A total of 1064 heat-related deaths were recorded for all 49 subdistricts in 2013 summer. 
Table 1: Properties of the Landsat 8 images used in this study.

\begin{tabular}{lccc}
\hline Landsat ID & Acquisition date & Local time & Cloud cover (\%) \\
\hline LC08_L1TP_119039_20130617_20170503_01_T1 & $2013 / 06 / 17$ & $10: 33: 32$ & 18.93 \\
LC08_L1TP_119039_20130703_20170503_01_T1 & $2013 / 07 / 13$ & $10: 33: 33$ & 60.32 \\
LC08_L1TP_119039_20130719_20170503_01_T1 & $2013 / 07 / 19$ & $10: 33: 33$ & 4.45 \\
LC08_L1TP_119039_20130804_20170503_01_T1 & $2013 / 08 / 14$ & $10: 33: 35$ & 56.54 \\
LC08_L1TP_119039_20130820_20170502_01_T1 & $2013 / 08 / 20$ & $10: 33: 36$ & 68.33 \\
\hline
\end{tabular}

2.2.2. Data Preprocessing and Normalization. Heat vulnerability refers to the propensity to be adversely affected and generally defined by the person or group characteristics and the socioeconomic statuses that influence the ability to anticipate, resist, and recover from extreme heat events $[28,29]$. An increasing number of studies have demonstrated multidimensional vulnerability assessment indicators, and the most prevalent indicators of vulnerability include age, social isolation, and economic level, cooling shelters [28, 34, 44] (Table 2). Based on these previous studies and our study area, we considered the vulnerability dimensions.

(1) Age and Health Status. Age is an essential factor for vulnerability as the elderly and unhealthy seniors tend to be inherently more susceptible to heat exposure and have a higher mortality and hospital admission rates than the general population [55]. We derived the number of seniors $(65+)$ and unhealthy seniors (60+) from 2010 census data.

(2) Social Isolation. Seniors especially have been identified as another significant factor during heat waves and excessive heat events in general [55]. Living alone, possibly resulting in fewer contacts with family and friends, is a significant indicator of increased vulnerability. We used the number of population aged above 60 living alone from the 2010 census to represent the social isolation degree.

(3) Low-Educated Members. Low-educated members are likely to be more vulnerable to heat stress than high-educated ones [23], as they might not fully understand the relationship between changes in their living environment, as well as receiving the heat risk warning information. Previous studies have pointed out that individuals with an education level below high school tended to have higher heat-related death rates in U.S. cities $[22,56]$. We used the number of illiteracy population (15+) and population lower than high school education to represent low-educated members.

(4) Economic Factors. Economic factors play a crucial role in affecting an individual's vulnerability to heat hazards [23]. The poor are most likely to experience the highest risk because they often suffer from inadequate air conditioning [57]. Since there is no air conditioning data at the subdistrict level in Hangzhou, the economic factors can replace the air conditioning data to some extent. Disposable income was the chosen indicator to represent the economic status.

(5) Cooling Facilities. In addition to citizens' physical and economic status, cold places where the public can access air conditioning, such as supermarkets, shopping plazas, libraries, and bookstores, can also provide protective cooling shelters during extreme heat events [25]. We collected the number of cooling facilities in each subdistrict to represent the ability of external resistance from the public territory.

(6) Environment Exposure. LST is the most common indicator to represent the heat exposure. Meanwhile, the lack of green space represents the possibility of preventing heat exposure.

The increasing number of age, social isolation, and loweducated members stand for an increasing vulnerability, while the increasing number of disposable income and cooling facilities have an opposite direction on vulnerability. We used positive and negative normalization to normalize these five values to 0 and 1 , with 1 representing the highest level of vulnerability to heat hazards. Furthermore, we assumed that the importance of all these five indicators are the same and weight them equally. All indicators were aggregated and normalized to heat vulnerability index (HVI) with a range between 0 and 1 again, with 1 representing the highest level of heat vulnerability.

\subsection{Methods}

2.3.1. LST Retrieval. Previous studies usually used groundbased air temperature taken from standard meteorological stations [27, 34]. However, there are insufficient stations located in intracity which cannot estimate the air temperature gradient [18]. Therefore, remote sensing satellites are increasingly used to assess the heat hazard LST [7, 19, 25]. Using GEE, a relatively new platform with massive available satellite data and strong computation ability, we chose Landsat 8 surface reflectance tier 1 dataset to calculate the average LST between June and August in 2013. This dataset is the atmospherically corrected surface reflectance from the Landsat 8 OLI/TIRS sensors. Two thermal infrared (TIR) bands were processed for orthorectified brightness temperature, and other bands were processed for orthorectified surface reflectance [58]. Cloud, cloud shadow, and snow cover were detected and excluded from the images by using pixel quality band derived from the CFMASK algorithm (https://code.earthengine.google.com/). The LST based on satellite brightness temperature and emissivity was computed by the following equation [58]:

$$
\text { LST }=\frac{T_{\text {sensor }}}{1+\left(\lambda *\left(T_{\text {sensor }} / \alpha\right)\right) \ln (\varepsilon)},
$$

where LST is the land surface temperature in $K, T_{\text {sensor }}$ is the Band 10 brightness temperature in $K, \lambda$ is the wavelength of 
TABLE 2: Descriptive statistics for the vulnerability variables.

\begin{tabular}{lcc}
\hline Variables & Mean (standard deviation) & Range \\
\hline Number of elderly ( $\geq 65$ years) & $5631(2640)$ & $537-13124$ \\
Number of unhealthy seniors & $69(37)$ & $21-180$ \\
Number of elderly ( $\geq 60$ years) living alone & $761(467)$ & $195-2216$ \\
Number of illiteracy ( $\geq 15$ years) & $1433(1002)$ & $370-5677$ \\
Population less than high school education & $30282(16601)$ & $10031-95302$ \\
Disposable income & $3009(1561)$ & $929-8623$ \\
Cooling facilities & $35.3(10.4)$ & $18-59$ \\
LST & $304.8(1.73)$ & $299.6-307.1$ \\
Lack of green space & $0.83(0.45)$ & $0-1$ \\
\hline
\end{tabular}

emitted radiance in meters, $\alpha=1.438 * 10^{-2} \mathrm{Mk}$, and $\varepsilon$ is the surface emissivity.

For $\varepsilon$, it was necessary to correct the spectral emissivity using the NDVI value:

$$
\varepsilon=1.0094+0.047 \ln (\mathrm{NDVI}), \quad 0 \leq \mathrm{NDVI}<0.15 .
$$

Water $(\mathrm{NDVI}<0)$ was assigned a value of 0.9925 , urban impervious areas and bare soil $(0 \leq \mathrm{NDVI}<0.15)$ were assigned a value of 0.923 , and vegetation (NDVI $>0.727)$ was assigned a value of 0.986 [59]. Otherwise, there was a modeling relationship with the NDVI values through the log-transform equation [60].

In order to acquire surface emissivity, we calculated NDVI using the following formulas:

$$
\mathrm{NDVI}=\frac{(\mathrm{NIR}-\mathrm{RED})}{(\mathrm{NIR}+\mathrm{RED})}
$$

where NIR is the reflectance in the near-infrared waveband (Band 5 for Landsat 8) and RED is the reflectance of visiblered waveband (Band 4 for Landsat 8 ).

Finally, the zonal statistics tool in ArcGIS was used to calculate the mean value of LST for each subdistrict.

2.3.2. Equal Weight Approach (EWA) and Principal Component Analysis (PCA). After the processing of indicators in Section 2.3.2, we assumed all nine indicators had the same influence on the heat vulnerability, and we added these indicators with equal weights to get the final vulnerability $\left(\mathrm{HVI}_{\mathrm{EWA}}\right)$.

PCA was usually employed in heat vulnerability studies to reduce the number of indicators [61]. The varimax rotation was used in PCA to ensure orthogonality between the reduced indicators, which could enhance the ability to covert correlated indicators to linearly uncorrelated components. We conducted all the PCA method in IBM SPSS 20.0. Since increasing variables indicate an increase in heat vulnerability, higher component scores also imply a higher heat vulnerability ( $\left.\mathrm{HVI}_{\mathrm{PCA}}\right)$.

To better compare the HVI generated from these two methods, the mean-standard deviation classification method was used to assign the HVI degree (Table 3).

2.3.3. Validation Method. Previous studies of vulnerability assessment were often validated by the qualitative method $[33,62]$, which might not provide the same reliability as
TABle 3: Assigning HVI values to results of EWA and PCA.

\begin{tabular}{lc}
\hline Range $(R)$ & Assigned HVI values \\
\hline$R<M-1.25 \mathrm{SD}$ & -3 \\
$M-1.75 \mathrm{SD} \leq R<M-0.75 \mathrm{SD}$ & -2 \\
$M-0.75 \mathrm{SD} \leq R<M-0.25 \mathrm{SD}$ & -1 \\
$M-0.25 \mathrm{SD} \leq R<M+0.25 \mathrm{SD}$ & 0 \\
$M+0.25 \mathrm{SD} \leq R<M+0.75 \mathrm{SD}$ & 1 \\
$M+0.75 \mathrm{SD} \leq R<M+1.25 \mathrm{SD}$ & 2 \\
$M+1.25 \mathrm{SD} \leq R$ & 3
\end{tabular}

quantitative validation. In this study, regression analysis had been used to establish the relationship between the total heat-related deaths and $\mathrm{HVI}_{\mathrm{EWA}}$ and $\mathrm{HVI}_{\mathrm{PCA}}$, respectively.

\section{Results}

3.1. LST Distribution. The mean LST values at the pixel level show that Hangzhou was experiencing high surface temperature from June to August in 2013 (Figure 2(a)). Under the heatwave background, the LST value ranges from 291.6 to $318.7 \mathrm{~K}$. Large scattered warming area exists in the central and northeast of the city; it is worth noting that this high LST are mainly distributed in the highly urbanized areas of Hangzhou. We combined these areas with Google Earth and recognized that the high LST is mostly distributed in three typical areas: (1) high-density old residences, (2) villages in urban and suburban areas, and (3) industrial zones which relieve heat energy forcing the air temperature (e.g., anthropic thermal and industrial thermal). However, the low LST is mainly located in the natural landscape, such as rivers, lakes, parks, and forests.

After the zonal statistics and normalization, the HHI values were categorized into five classes from 0 to 1 using the natural breaks method (Figure 2(b)). Overall, the LST patterns show a gradient decreasing trend from urban centers to suburban areas. At the subdistrict level, significant spatial heterogeneity in LST distribution patterns can be identified. Subdistricts with highest LST (0.87-1.00) were mainly observed in the city center, including Caihe, Changqing, Cuiyuan, Pengbu, Shiqiao, Tianshui, Wangjiang, Wulin, Xixing, Xiaoying, and Zhanongkou, where population density is pretty high, and vegetation coverage is small among all 49 subdistricts. The lowest LST values (0.00-0.40) can be found in the Xihu district in the southwest. 

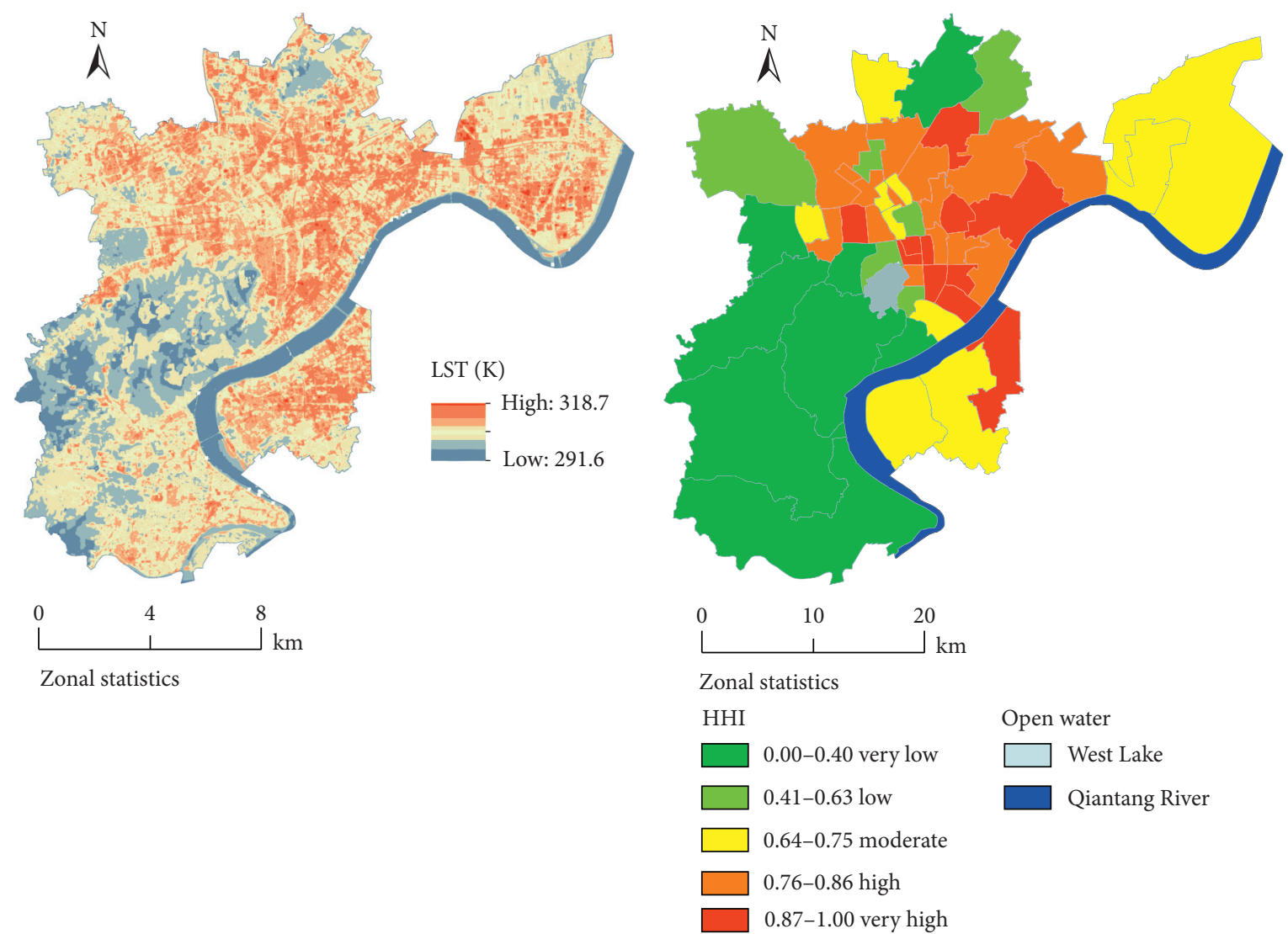

(a)

(b)

Figure 2: (a) The mean LST (June to August) at the pixel level; (b) the mean HHI at the subdistrict level.

3.2. Spatial Distribution of Heat Vulnerability Using EWA. We visualized the spatial patterns of these nine indicators and the HVI using the same weight combination method (Figure 3). Indicators such as the number of elderly, the number of elderly living alone, unhealthy seniors, and LST show that high values in the urban center and low values in the surrounding area. These results indicate that the elder tends to live in the urban center. In contrast, the number of illiteracy and the population less than high school education show the gradient increasing trend from the urban center to the periphery of the study area. Variables such as income, cooling facilities, and lack of green space have a strong spatial heterogeneity distribution but do not show a clear spatial distribution rule.

After combining these nine variables using an equal weight method, the HVI values in Table 3 had been assigned to $\mathrm{HVI}_{\mathrm{EWA}}$ (Figure 4). In general, the spatial distribution of heat vulnerability shows that the areas with the higher heat vulnerability are concentrated in the urban center, while the areas with the lower heat vulnerability are located in the surrounding suburban area. The differences between Figures 4(a) and 4(b) are caused by different classification methods. Figure 4(a) shows the spatial pattern of HVI $\mathrm{EWA}_{\mathrm{E}}$ using the natural breakpoint method into five levels, while Figure 4(b) exhibits the spatial pattern of $\mathrm{HVI}_{\mathrm{EWA}}$ using the mean-standard deviation method (Table 3). Using the mean- standard deviation method, we found a total of five subdistricts, including Xiaoying, Ziyang, Wangjiang, Dongxin, and Caihe, show the HVI value of 3 , which indicates that these subdistricts have the relatively highest vulnerability to heat exposure. Subdistricts with the lowest HVI value are mainly located in the east and north, for example, Linyin, Liuxia, Jiangcun, Xihu, Beishan, and Dingqiao.

3.3. Spatial Distribution of Heat Vulnerability Using PCA. The PCA method grouped the nine vulnerability indicators into three independent components (Table 4). The cumulative contribution of the three components is $81.784 \%$, which means that $81.784 \%$ variance of raw vulnerability indicators can be explained by these three independent components. The first component explains $42.005 \%$ of the total variance, followed by $21.886 \%$ and $17.893 \%$ for the second and the third components, respectively.

The first component includes education less than high school, income, unhealthy seniors, elderly living alone, and illiteracy. The second component can be characterized by the elderly population and cooling facilities. Component 3 can be characterized by the lack of green space and LST (Table 5).

The spatial pattern of each component is shown in Figure 5. The subdistricts with the highest HVI value are found in the urban center and the northwest and northeast 

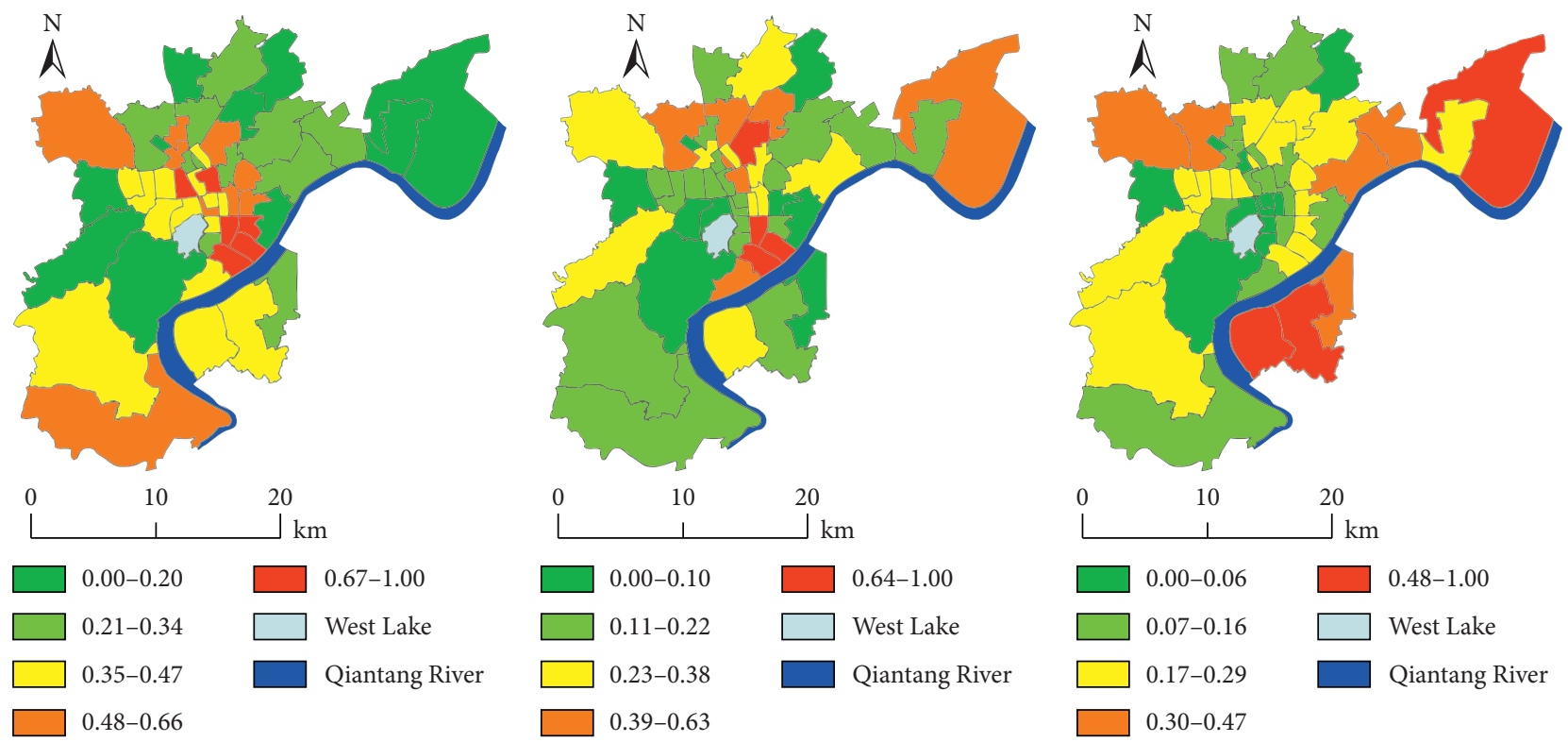

(a)

(b)

(c)
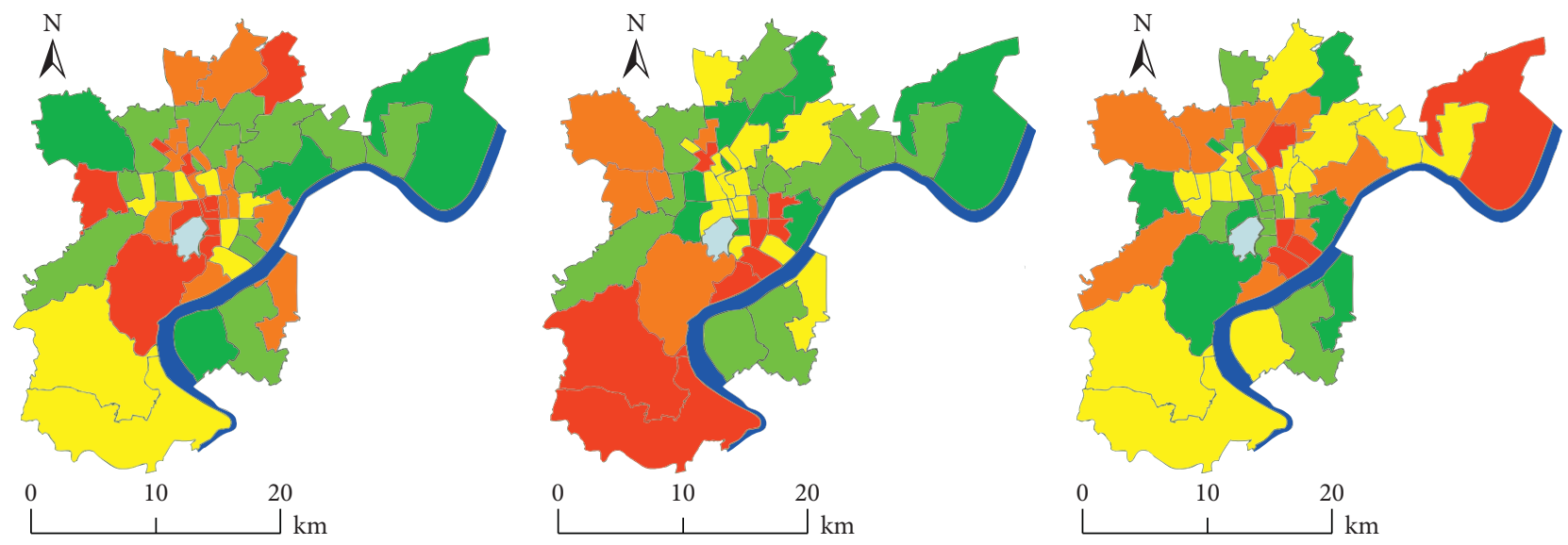

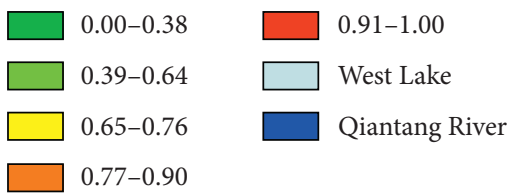

(d)

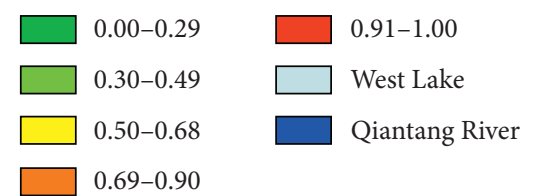

(e)

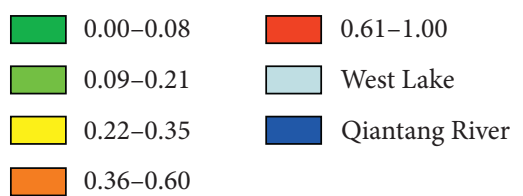

(f)

Figure 3: Continued. 

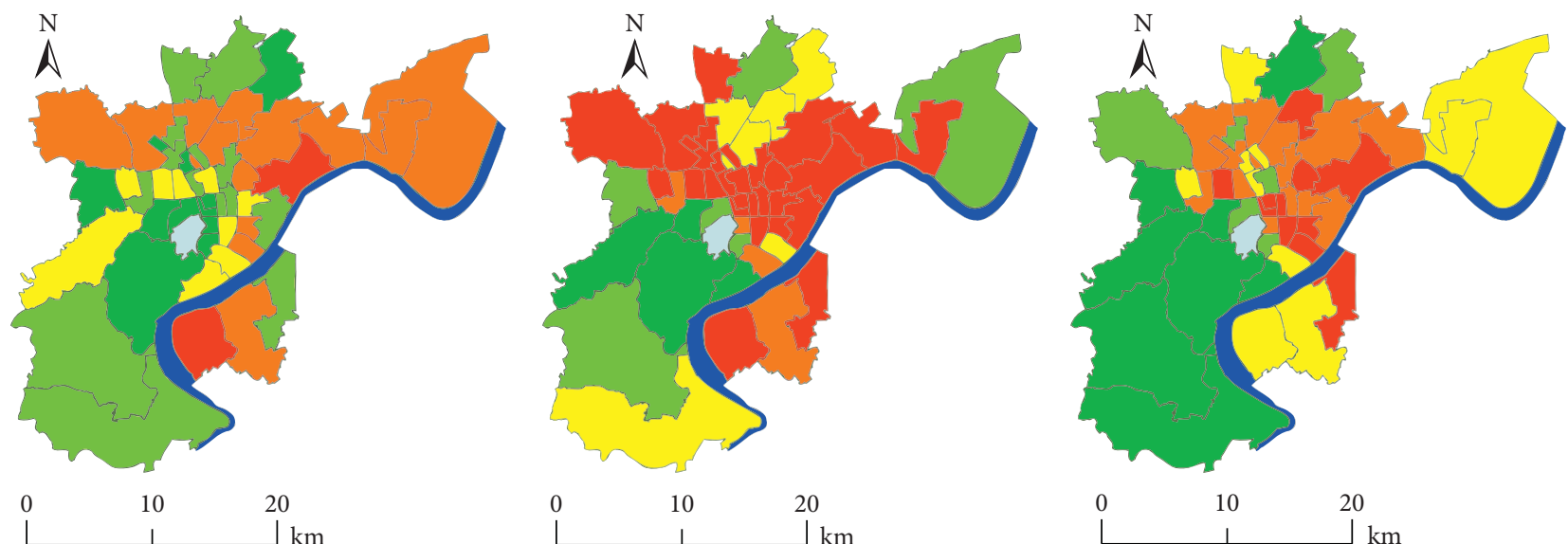

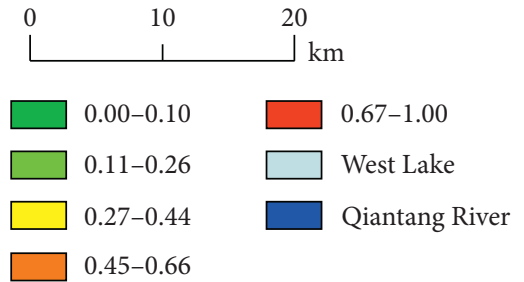

(g)

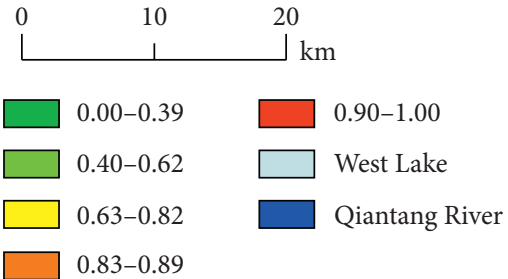

(h)

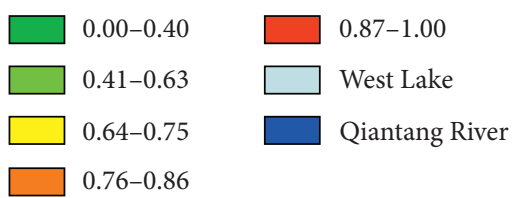

(i)

FIGURE 3: Spatial distribution of heat vulnerability variables in Hangzhou: (a) age $\geq 65$ years; (b) age $\geq 60$ living alone; (c) illiteracy; (d) income; (e) cool facilities; (f) unhealthy seniors; (g) population less than high school education; (h) lack of green space; (i) LST (same as Figure 2) for Hangzhou at the subdistrict level.
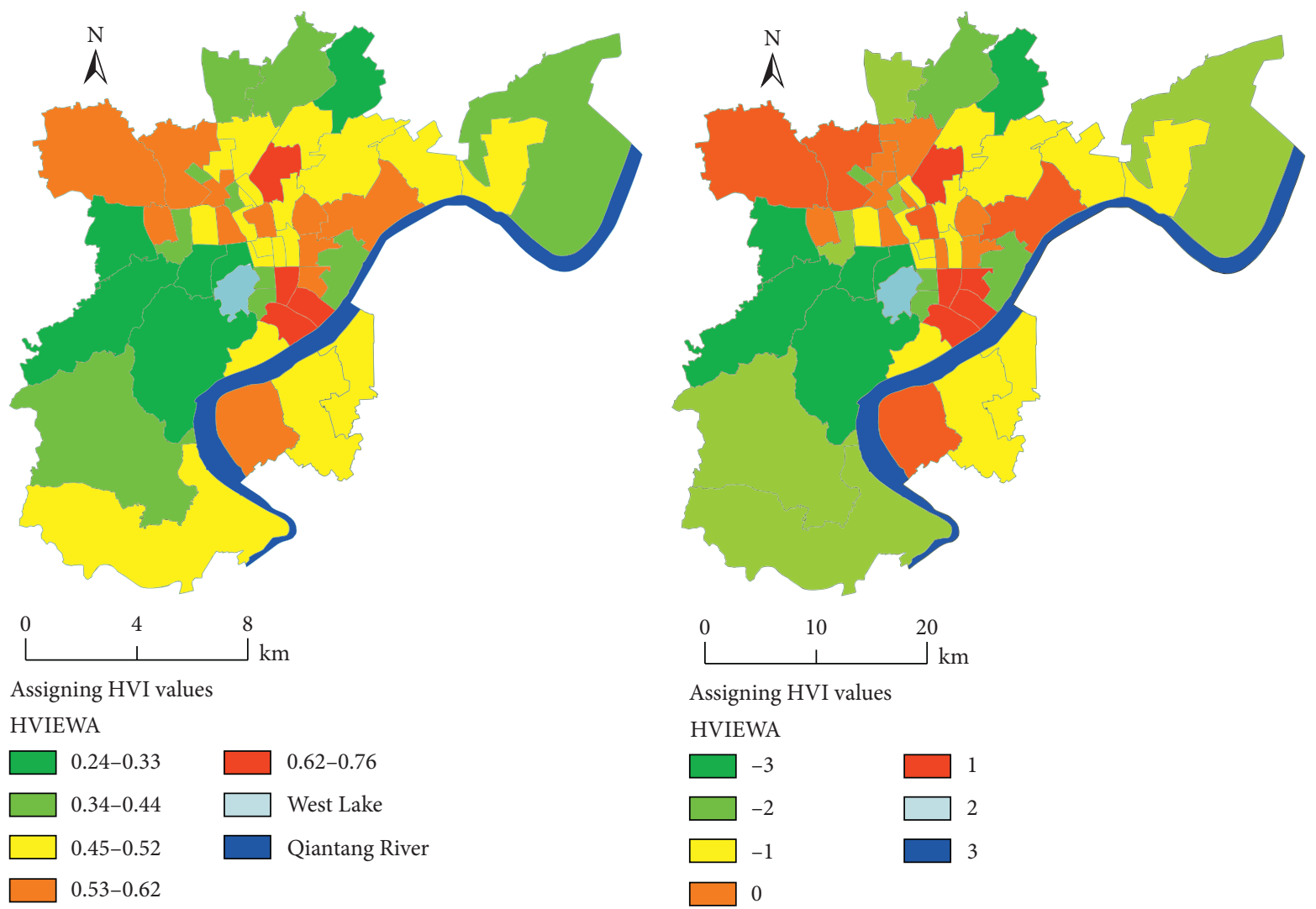

(a)

(b)

FIgURE 4: (a) The spatial distribution of HVI in Hangzhou using EWA at the pixel level; (b) the spatial distribution of HVI after assigning HVI values. 
TABLE 4: Total variance explained in the PCA method.

\begin{tabular}{|c|c|c|c|c|c|c|}
\hline \multirow{2}{*}{ Component } & \multicolumn{3}{|c|}{ Initial eigenvalues } & \multicolumn{3}{|c|}{ Extraction sums of squared loadings } \\
\hline & Total & $\%$ of variance & Cumulative \% & Total & $\%$ of variance & Cumulative \% \\
\hline 1 & 3.78 & 42.005 & 42.005 & 3.78 & 42.005 & 42.005 \\
\hline 2 & 1.97 & 21.886 & 63.891 & 1.97 & 21.886 & 63.891 \\
\hline 3 & 1.61 & 17.893 & 81.784 & 1.61 & 17.893 & 81.784 \\
\hline 4 & 0.887 & 9.850 & 91.635 & & & \\
\hline 5 & 0.339 & 3.767 & 95.402 & & & \\
\hline 6 & 0.159 & 1.762 & 97.164 & & & \\
\hline 7 & 0.138 & 1.536 & 98.700 & & & \\
\hline 8 & 0.103 & 1.142 & 99.842 & & & \\
\hline 9 & 0.014 & 0.158 & 100.00 & & & \\
\hline
\end{tabular}

TABLE 5: Component matrix from the PCA method.

\begin{tabular}{lccc}
\hline Indicators & \multicolumn{2}{c}{ Component } \\
& 1 & 2 & -0.024 \\
\hline Education less than high school & $\mathbf{0 . 8 9 5}$ & -0.257 & 0.07 \\
Income & $-\mathbf{0 . 8 6 2}$ & 0.411 & -0.401 \\
Unhealthy seniors & $\mathbf{0 . 8 1 5}$ & 0.251 & -0.365 \\
Elderly living alone & $\mathbf{0 . 7 4 7}$ & -0.531 & 0.054 \\
Illiteracy & $\mathbf{0 . 7 1 4}$ & $\mathbf{0 . 7 8 8}$ & -0.137 \\
Elderly (65+) & 0.346 & $\mathbf{0 . 6 0}$ & -0.448 \\
Cooling facilities & -0.156 & 0.39 & $\mathbf{0 . 7 6 2}$ \\
Lack of green space & 0.373 & 0.404 & $\mathbf{0 . 7 1 3}$ \\
LST & 0.47 & 0.604 & \\
\hline
\end{tabular}

Note: the bold numbers indicate that each component is characterized by indicators with a correlation of magnitude 0.6 or higher with the corresponding component. For example, Component $1=\mathrm{a} *$ education $+\mathrm{b} *$ income $+\mathrm{c} *$ unhealthy seniors $+\mathrm{d} *$ elderly living along $+\mathrm{e} *$ illiteracy.

part of the study area, which means that the dominant indicators of Component 1 have a relatively higher value in those regions (Figure 5(a)). The subdistricts with lower HVI values mainly surrounded the West Lake encircling the inner city and the north of the suburban area. The dominant indicators of Component 2 are elderly people and cooling facilities. It can be seen that the subdistricts with the highest HVI value of Component 2 are mainly located in the urban center, which indicated that those regions had a relatively high number of elderly or the number of cooling facilities was relative low (Figure 5(b)). Lack of green space and LST are the dominant indicators of Component 3 . It can be seen that there is no highest HVI value in the spatial distribution of Component 3 (Figure 5(c)). Unlike the other two components, the spatial pattern of Component 3 shows an obvious aggregation characteristic with a higher HVI value located in the northeast and the lowest HVI value concentrated in the southwest.

After aggregating three components into the final HVI through different weight factors, the spatial distribution of $\mathrm{HVI}_{\mathrm{PCA}}$ can be found in Figure 5(d). In general, the pattern of $\mathrm{HVI}_{\mathrm{PCA}}$ shows that subdistricts with higher HVI values are located in the urban center, while those with lower HVI values are located in the suburban area. Subdistricts with the highest vulnerability can be found in Xiaoying, Ziyang, Wangjiang, Pengbu, Sandu, Puyan, and Dongxin. Subdistricts with the lowest HVI value can be found in Liuxia, Dingqiao, Linyin, Jiangcun, Xihu, and Beishan.
3.4. Comparison between $H V I_{E W A}$ and $H V I_{P C A}$. We compared the different level degrees between $\mathrm{HVI}_{\mathrm{EWA}}$ and $\mathrm{HVI}_{\mathrm{PCA}}\left(\mathrm{HVI}_{\mathrm{EWA}}\right.$ minus $\mathrm{HVI}_{\mathrm{PCA}}$ ) (Figure 6). The white regions represent that the HVI level in two methods remains the same. It can be seen that the HVI level of 26 subdistricts keeps constant, where most of them are mainly located in the urban center and southwest of the study area. Comparing to the $\mathrm{HVI}_{\mathrm{EWA}}$, the HVI of PCA method tended to underestimate the heat vulnerability of the urban center, while tended to overestimate the heat vulnerability of the suburban area in the northeast and northwest of the study area.

To compare the accuracy of these two HVI results, we built the relationship between the total heat-related death and $\mathrm{HVI}_{\mathrm{EWA}}$ and $\mathrm{HVI}_{\mathrm{PCA}}$, respectively (Figure 7). In the current study, we collected heat-related deaths at the subdistrict level $(n=49)$ to assess the reliability of $\mathrm{HVI}_{\mathrm{EWA}}$ and $\mathrm{HVI}_{\mathrm{PCA}}$. Linear regression was used to predict heat-related deaths using the $\mathrm{HVI}_{\mathrm{EWA}}$ and $\mathrm{HVI}_{\mathrm{PCA}}$ as the independent variable. The result suggests that the $\mathrm{HVI}_{\mathrm{EWA}}$ shows a greater correlation with the heat-related deaths with an $R^{2}$ of 0.58 than $\mathrm{HVI}_{\mathrm{PCA}}$ with an $R^{2}$ of 0.32 .

\section{Discussion}

4.1. Spatial Distribution of LST in Hangzhou. Previous studies have shown that high-temperature zones are usually located in the impervious surface such as residential areas and industrial areas, which are mainly caused by the 

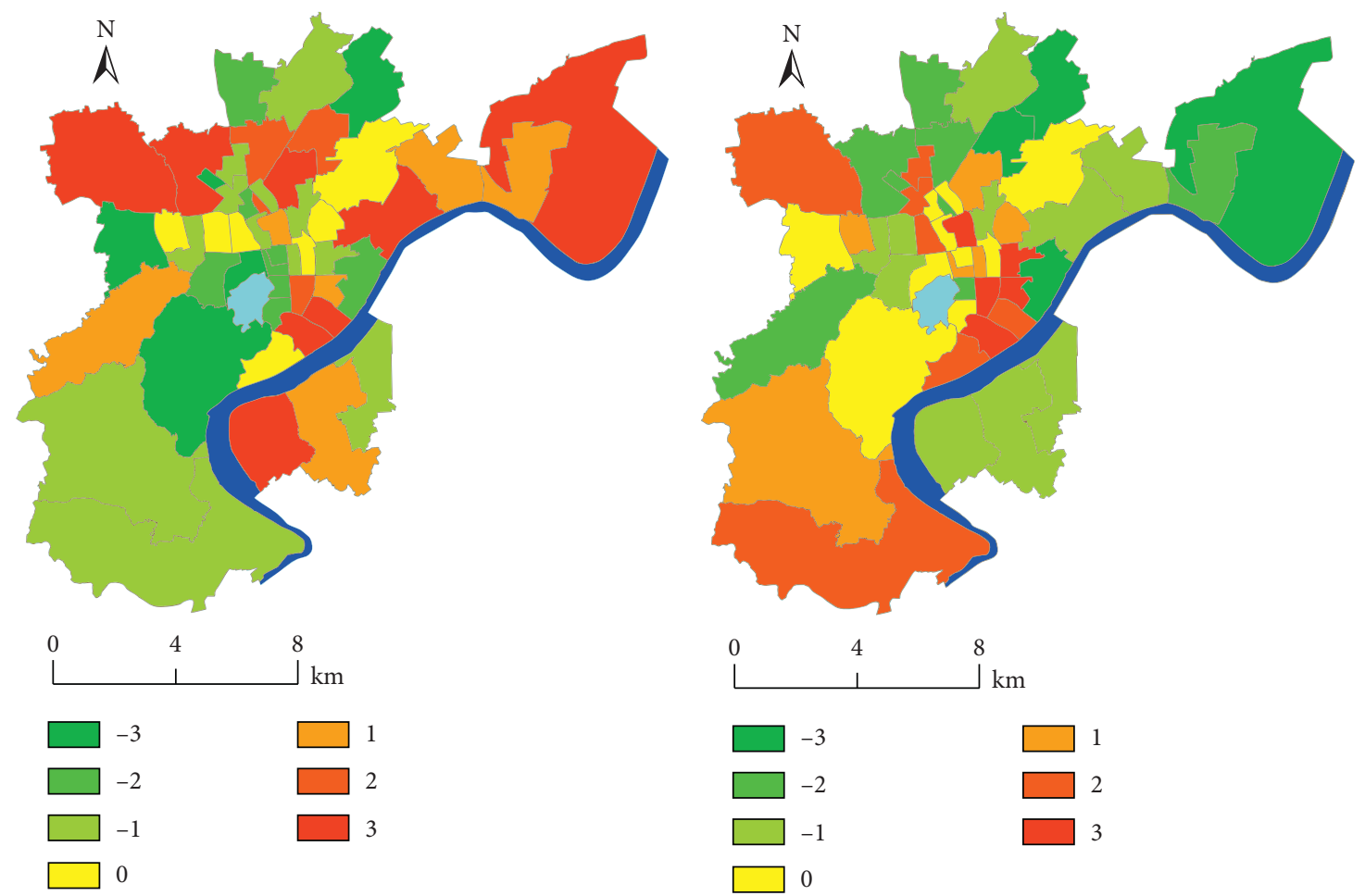

(a)
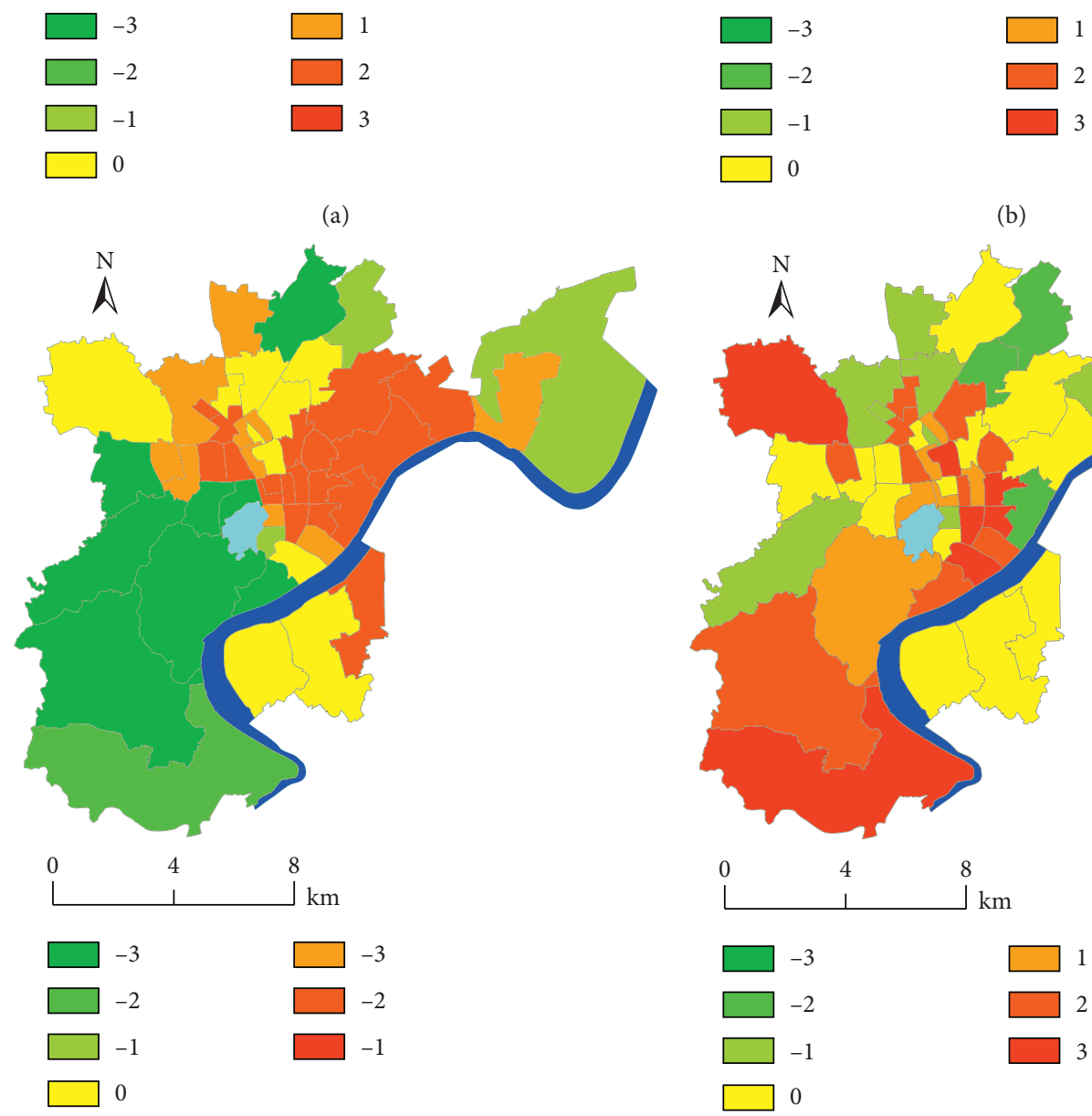

(b)

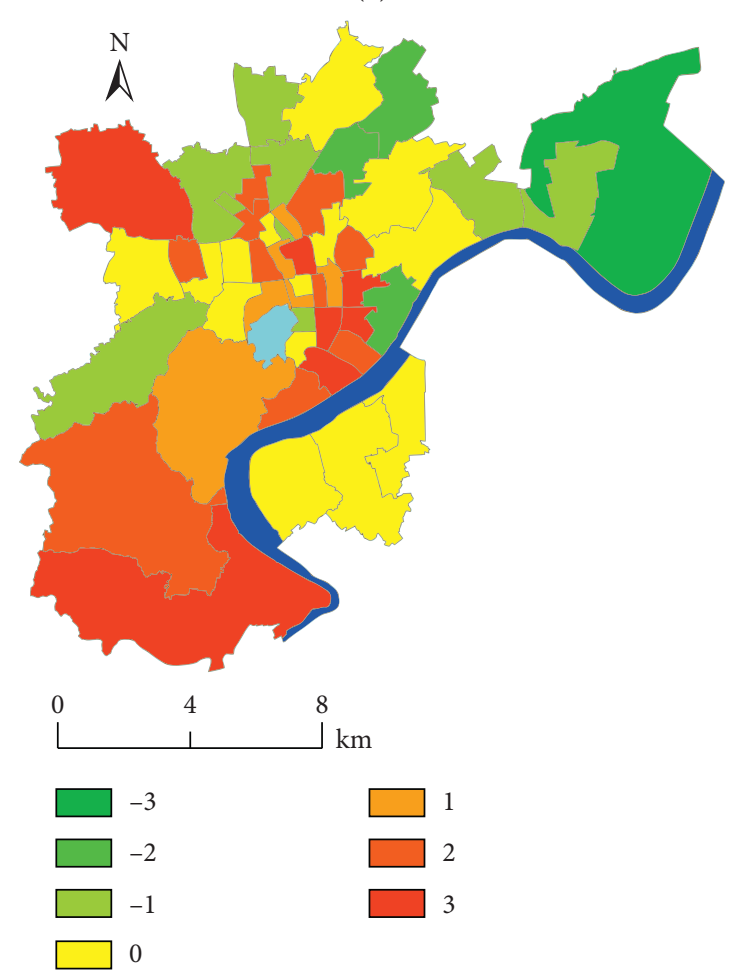

(c)

(d)

FIGURE 5: Spatial distributions of heat vulnerability using the PCA method: (a) Component 1: education/income/unhealthy seniors/elderly living along/illiteracy; (b) Component 2: elderly/cooling facilities; (c) Component 3: lack of green space/LST; (d) the final vulnerability through aggregating three components.

characteristics of the underlying surface and the anthropogenic heat emission from human metabolism and industrial production and residential life $[52,63,64]$. The impervious surface of artificial land commonly has a low albedo, which will absorb more heat and lead to a higher surface temperature $[65,66]$. Meanwhile, the anthropogenic 


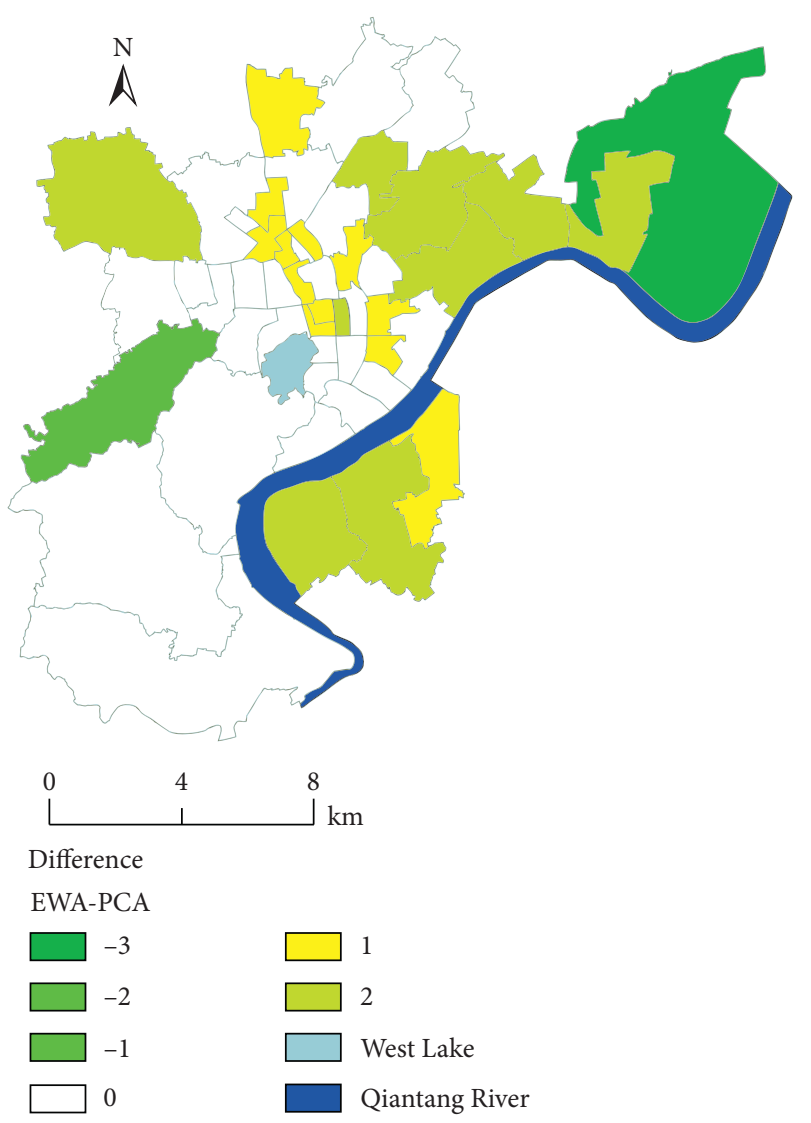

FIgURE 6: The regression between HRI and heat-related deaths at the subdistrict level.

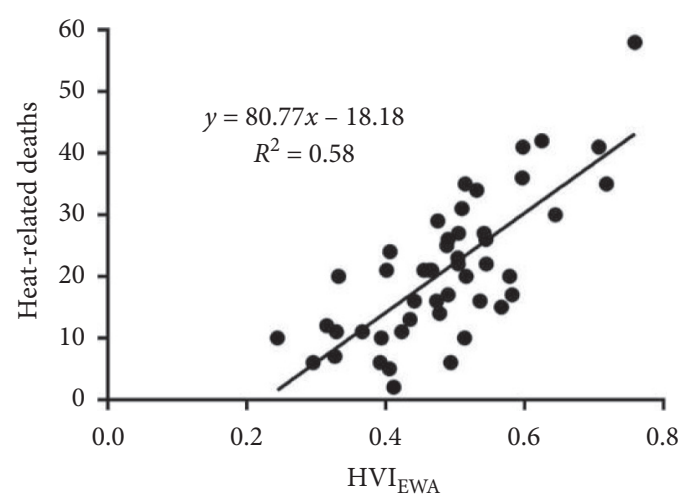

(a)

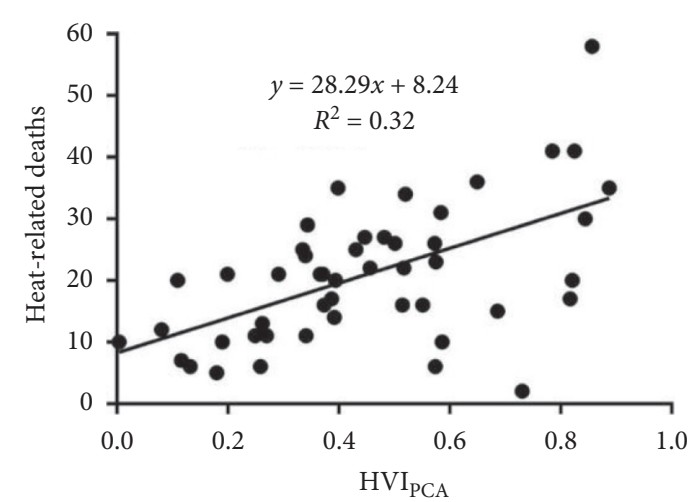

(b)

FIgURE 7: The correlation between the heat-related deaths and (a) HVI $\mathrm{EWA}_{\mathrm{E}}$ and (b) HVI $\mathrm{PCA}_{\text {. }}$

heat derived from human activities, including building energy consumption, transportation, industrial heat emission, and human metabolism, is another heat source for the population or industry cluster zones [67, 68]. Both the characteristics of impervious surface and human activities cause the high LST distributes in the above area. For the low LST distribution, latent heat flux plays a crucial role in keeping the temperature at a cooling level [63]. On the one hand, water and vegetation have a lower heat absorption due to its relatively high thermal inertia [64]. On the other hand, evaporation of water and evapotranspiration of vegetation will bring out the heat, which will cause the lower surface temperature [66]. The spatial pattern of LST in our study is consistent with previous studies in Hangzhou, which exhibited that high land surface temperature exists in the central and northeast city, while low temperature areas are observed in southwest $[36,69,70]$. This similar situation has occurred in other relative studies, not just Hangzhou. Studies using LST or air temperature exhibited higher values located in the central area as well $[18,19,34]$. 
One of the significant differences of LST between our study and previous studies is that previous studies usually select one remotely sensed image to represent the heat distribution $[18,19,44]$. However, our study calculates the average thermal image of the summer using GEE. The strong cloud calculation function and massive Landsat images in the GEE platform provide us with an excellent opportunity to extract average LST spatial patterns. Compared to the GEE, conventional methods to retrieve LST require highperformance computer hardware and satellite images download $[49,70]$. Moreover, the LST based on single scene data would be confined to a specific day, which cannot represent the general spatiotemporal heat hazard environment [36]. A recent study showed that using GEE to obtain LST in Hangzhou could avoid image quality and present better general features of urban heat island when compared to the conventional method $[36,49]$. As more functions and satellite datasets are integrated into the GEE platform, the extraction of remote sensing information via GEE is becoming more and more popular, which is beneficial for the heat hazard estimation.

\subsection{Spatial Distribution of Heat Vulnerability of Hangzhou.} Previous studies using the meta-analysis approach have explored that the urban vulnerability is related to many factors, such as temperature level, population, age, gender, education, income, access to home amenities, or public cooling facilities $[14,25]$. By considering the local characters, we selected nine variables to build HVI using an equal weight approach (EWA) and principal component analysis (PCA). Although two vulnerability results exhibit a certain degree of difference, they both demonstrate that the central area might be more vulnerable to oppressive heat than outlying parts. By contrast, intriguing but conflicting results exist in previous research about who exactly the most vulnerable to extreme heat is. Some studies have demonstrated that downtown areas are more vulnerable than outlying areas $[24,28,71,72]$, while others have indicated that rural residents are more susceptible [73]. There may exist multiple possible explanations for our outcome. The high number of elderly people and elderly people living alone is concentrated in the downtown area. Meanwhile, the number of cooling facilities in outlying parts was observed to be larger than the central area. Also, our result is consistent with the previous study, which showed that vulnerability increased in warmer neighborhoods which tended to be located in the inner city [24].

4.3. Reasons of Differences between $H V I_{E W A}$ and $H V I_{P C A}$. Our results show the substantial differences of heat vulnerability using EWA and PCA. The $\mathrm{HVI}_{\mathrm{PCA}}$ had less success in explaining the total heat-related deaths, with a low correlation between models. Furthermore, $\mathrm{HVI}_{\mathrm{EWA}}$ performed a much better correlation with the number of death accompanying higher $R^{2}$. This difference is mainly caused by the different weight factors being used in our study. In the process of the PCA method, the linear combination of several indicators to explain the most variation of variables will reduce the dimensionality of the data. This linear combination usually involves the different weights of aimed indicators [33]. Besides, if several indicators representing a similar aspect increases, the indicators of this aspect will be inevitably magnified [33]. In our case, the elderly (60+) living alone and unhealthy seniors both belong to Component 1 , which will increase the weight of the elderly population. In the equal weight approach, the selected indicators were assumed to indicate the different aspects of vulnerability, and the weight of each indicator remains the same. Therefore, the PCA method may confound several significant information on heat vulnerability to inform planning response, which means reducing multiple indicators into fewer dimensions could cause an impact on the result of vulnerability.

4.4. Potential Strategies to Mitigate the High Heat Vulnerability. Although the results from $\mathrm{HVI}_{\mathrm{EWA}}$ and $\mathrm{HVI}_{\mathrm{PCA}}$ are different, there are commonalities that four districts, including Xiaoying, Ziyang, Wangjiang, and Dongxin, have the highest HVI scores (HVI value 3) in both situations. However, the dominant vulnerability components of these four subdistricts are various. For instance, Xiaoying has the highest number of age $65+$, the high number of the elder living alone, high LST, few cooling facilities, and few green coverages. Ziyang has a high number of the elder living alone, a high number of unhealthy seniors, and a high number of the elder living alone. Wangjiang has the highest number of the elder living alone, the highest number of unhealthy seniors, and the highest LST. Dongxin has a high number of the elder living alone and high LST.

Although the dominant components of each subdistrict with high HVI are different, they can be roughly divided into three types: high surface temperature, lots of elderly, and lack of cooling places. It can be seen that three of these four subdistricts have a high LST problem. Theoretically, the more divided and complex shape of the built-up area can provide a more reduction of UHI intensity if the total builtup areas are held constant [52]. However, it must be significantly difficult to alter the spatial structure of the built-up area in reality, not to mention that these three subdistricts are located in the center area. Meanwhile, planting vegetation in the urbanized area seems to be a great choice since it can both increase the division of the built-up area and provide an extracooling effect [52, 64, 74]. Besides, more vegetation will also provide temporary green shelter for people outdoors.

For the subdistricts with many elderly people, community workers should firstly take measures to reduce social isolation and loneliness. The elderly people are limited by problems such as limited mobility, slow knowledge reception, and death of relatives, which would cause social isolation and loneliness and many elderly people die in extreme heat events $[1,10]$. Therefore, necessary services, such as housing adaptation, telephones, and alarms, should be provided by local community authorities to the elderly. In addition, medicines and foods for preventing heat stroke should be delivered to those in need, especially people with 
potential diseases. Finally, community workers should announce the dangers of heat vulnerability to improve the selfprotection awareness of the elderly.

For the subdistricts lacking cooling facilities, the local government should call for more cooling facilities to open for the vulnerable people. Meanwhile, it can provide certain subsidies for the elderly to purchase the cooling equipment to reduce their heat vulnerability. Mitigating heat vulnerability is not a simple matter, which requires the top-down multiparticipation and specific mitigation strategies for specific areas.

4.5. Limitations of This Study. There are several limitations associated with our study. First, some potentially relative data, such as the number of air condition and building characteristics, are not included in this study, which could cause some uncertainties of HVI prediction results. The correlation between the heat-related death and assessed HVI is not very high, which also demonstrates that the existing data cannot fully reflect the actual distribution of HVI. In the future, the effective collection and application of multisource data will further improve the accuracy of HVI assessment.

Secondly, although this study has shown that the HVI using the EWA method has a higher correlation with heatrelated death than HVI using PCA, it does not indicate that EWA is the most suitable method to assess HVI. It is recognized in this study that the component of the elderly (age $65+$ ) has a high correlation with heat-related death, and the degree of lack of green space can act as a predictor for the LST. As a result, this EWA method can impact the accuracy of HVI assessment. In the future, multicriteria methods should be used to improve the HVI analysis.

Thirdly, this study only focuses on one year of HVI. Analyzing the HVI in different years and predicting the temporal trend would allow the HVI assessment to be more reliable.

\section{Conclusions}

This study assessed the heat vulnerability at the subdistrict level in the urban area of Hangzhou using an equal weight approach (EWA) and principal component analysis (PCA). Firstly, we employed a novel approach for retrieval of mean land surface temperature (LST) (June-August 2013) from the Google Earth Engine (GEE) platform as one indicator of heat vulnerability to avoid the cloud-contaminated data problem. Secondly, we collected demographic data, essential geographic data, and socioeconomic data. Thirdly, we built the two different HVI based on EWA and PCA, respectively. Finally, we applied heat-related death data to compare the accuracy of $\mathrm{HVI}_{\mathrm{EWA}}$ and $\mathrm{HVI}_{\mathrm{PCA}}$.

In particular, we reached the following conclusions: (1) both $\mathrm{HVI}_{\mathrm{EWA}}$ and $\mathrm{HVI}_{\mathrm{PCA}}$ show that the high vulnerability of intracity in Hangzhou located in the urban core area, with a decreasing trend from the inner city center to the edge of Hangzhou. (2) The comparison between $\mathrm{HVI}_{\mathrm{EWA}}$ and HVI $_{\mathrm{PCA}}$ shows $\mathrm{HVI}_{\mathrm{PCA}}$ underestimates the heat vulnerability of the urban center, while tended to overestimate the heat vulnerability of the suburban area. (3) The significant correlation between $\mathrm{HVI}_{\mathrm{EWA}}$ and heat-related deaths performs better than the correlation between $\mathrm{HVI}_{\mathrm{PCA}}$ and heatrelated death, which implies that EWA could be a better approach to vulnerability estimation. (4) To reduce the heat vulnerability, for example, subdistricts with high heat vulnerability can concentrate on the ways to provide cooling facilities for the economically vulnerable people, or the administers can offer special care for seniors, especially for the old with social isolation.

Comparing two simple approaches at the smallest administrative unit in China provide valuable decision support in directing heat vulnerability mitigation. On a subdistrict level, mapping heat vulnerability can be accurate, and heat vulnerability mitigation plans and emergency management can target efforts even more effectively. Future research is needed to identify heat risk in multiple years and assess the changing trend, which could provide more reliable heat vulnerability maps for heat vulnerability warning systems and heat vulnerability mitigation.

\section{Data Availability}

Data for this work are available from the corresponding author upon request.

\section{Conflicts of Interest}

The authors declare that there are no conflicts of interest regarding the publication of this paper.

\section{Acknowledgments}

The first author would like to thank the China Scholarship Council. This work was supported by the National Natural Science Foundation of China (nos. 41671533 and 41871169), Fundamental Research Funds for the Central Universities, Ministry of Education in China Liberal arts and Social Sciences Foundation (no. 20XJCZH009), and High-Level Talents Program of Hainan Provincial Natural Science Foundation of China (no. 2019RC122).

\section{References}

[1] K. Akerlof, R. DeBono, P. Berry et al., "Public perceptions of climate change as a human health risk: surveys of the United States, Canada and Malta," International Journal of Environmental Research and Public Health, vol. 7, no. 6, pp. 2559-2606, 2010.

[2] G. A. Leiserowitz and C. Tebaldi, "More intense, more frequent, and longer lasting heat waves in the 21st century," Science, vol. 305, no. 5686, pp. 994-997, 2004.

[3] R. L. Wilby, "Constructing climate change scenarios of urban heat island intensity and air quality," Environment and Planning B: Planning and Design, vol. 35, no. 5, pp. 902-919, 2008.

[4] S. N. Gosling, E. K. Bryce, P. G. Dixon et al., "A glossary for biometeorology," International Journal of Biometeorology, vol. 58, no. 2, pp. 277-308, 2014.

[5] M. L. Gabriel, M. S. O’Neill, N. Ranjit, V. H. Borja-Aburto, L. A. Cifuentes, and N. C. Gouveia, "Vulnerability to heat- 
related mortality in Latin America: a case-crossover study in São Paulo, Brazil, Santiago, Chile and Mexico City, Mexico," International Journal of Epidemiology, vol. 37, no. 4, pp. 796-804, 2008.

[6] J. L. Dickinson, "The people paradox: self-esteem striving, immortality ideologies, and human response to climate change," Ecology and Society, vol. 14, no. 1, 2009.

[7] D. P. Johnson, A. Stanforth, V. Lulla, and G. Luber, "Developing an applied extreme heat vulnerability index utilizing socioeconomic and environmental data," Applied Geography, vol. 35, no. 1-2, pp. 23-31, 2012.

[8] C. R. Browning, D. Wallace, S. L. Feinberg, and K. A. Cagney, "Neighborhood social processes, physical conditions, and disaster-related mortality: the case of the 1995 Chicago heat wave," American Sociological Review, vol. 71, no. 4, pp. 661-678, 2006.

[9] J. C. Semenza, C. H. Rubin, K. H. Falter et al., "Heat-related deaths during the July 1995 heat wave in Chicago," New England Journal of Medicine, vol. 335, no. 2, pp. 84-90, 1996.

[10] J.-M. Robine, S. L. K. Cheung, S. Le Roy et al., "Death toll exceeded 70,000 in Europe during the summer of 2003," Comptes Rendus Biologies, vol. 331, no. 2, pp. 171-178, 2008.

[11] R. Van Oyen, M. Hoerling, J. Perlwitz et al., "Was there a basis for anticipating the 2010 Russian heat wave?" Geophysical Research Letters, vol. 38, no. 6, 2011.

[12] B. Stone, J. J. Hess, and H. Frumkin, "Urban form and extreme heat events: are sprawling cities more vulnerable to climate change than compact cities?" Environmental Health Perspectives, vol. 118, no. 10, pp. 1425-1428, 2010.

[13] Department of Economic and Social Affairs, World Urbanization Prospects: The 2005 Revision; Population Division, United Nations, Department of Economic and Social Affairs, New York, NY, USA, 2006.

[14] P. Romero-Lankao, H. Qin, and K. Dickinson, "Urban vulnerability to temperature-related hazards: a meta-analysis and meta-knowledge approach," Global Environmental Change, vol. 22, no. 3, pp. 670-683, 2012.

[15] D. Johnson, V. Lulla, A. Stanforth, and J. Webber, "Remote sensing of heat-related health risks: the trend toward coupling socioeconomic and remotely sensed data," Geography Compass, vol. 5, no. 10, pp. 767-780, 2011.

[16] G. Maier, A. Grundstein, W. Jang, C. Li, L. P. Naeher, and M. Shepherd, "Assessing the performance of a vulnerability index during oppressive heat across Georgia, United States," Weather, Climate, and Society, vol. 6, no. 2, pp. 253-263, 2014.

[17] Y. Wang, X. Li, J. Li, Z. Huang, and R. Xiao, "Impact of rapid urbanization on vulnerability of land system from complex networks view: a methodological approach," Complexity, vol. 2018, Article ID 8561675, 18 pages, 2018.

[18] C. Buscail, E. Upegui, and J.-F. Viel, "Mapping heatwave health risk at the community level for public health action," International Journal of Health Geographics, vol. 11, no. 1, p. $38,2012$.

[19] C. J. Tomlinson, L. Chapman, J. E. Thornes, and C. J. Baker, "Including the urban heat island in spatial heat health risk assessment strategies: a case study for Birmingham, UK," International Journal of Health Geographics, vol. 10, no. 1, p. 42, 2011.

[20] S. Hajat, B. Armstrong, M. Baccini et al., "Impact of high temperatures on mortality," Epidemiology, vol. 17, no. 6, pp. 632-638, 2006.

[21] M. A. Paldy and M. Mirabelli, "The potential impacts of climate variability and change on temperature-related morbidity and mortality in the United States," Environmental Health Perspectives, vol. 109, p. 5, 2001.

[22] M. S. O'Neill, "Modifiers of the temperature and mortality association in seven US cities," American Journal of Epidemiology, vol. 157, no. 12, pp. 1074-1082, 2003.

[23] S. L. Harlan, A. J. Brazel, L. Prashad, W. L. Stefanov, and L. Larsen, "Neighborhood microclimates and vulnerability to heat stress," Social Science \& Medicine, vol. 63, no. 11, pp. 2847-2863, 2006.

[24] C. E. Reid, M. S. O’Neill, C. J. Gronlund, S. J. Brines, D. G. Brown, and A. V. Diez-Roux, "Mapping community determinants of heat vulnerability," Environmental Health Perspectives, vol. 117, no. 11, pp. 1730-1736, 2009.

[25] C. Schwartz, D. Patychuk, K. Bassil, S. Nasr, S. Gower, and M. Campbell, "The role of maps in neighborhood-level heat vulnerability assessment for the city of Toronto," Cartography and Geographic Information Science, vol. 37, no. 1, pp. 31-44, 2010.

[26] L. Vescovi, M. Rebetez, and F. Rong, “Assessing public health risk due to extremely high temperature events: climate and social parameters," Climate Research, vol. 30, pp. 71-78, 2005.

[27] B. Janicke, A. Holtmann, K. R. Kim, M. Kang, U. Fehrenbach, and D. Scherer, "Quantification and evaluation of intra-urban heat-stress variability in Seoul, Korea," International Journal of Biometeorology, vol. 63, no. 1, pp. 1-12, 2018.

[28] C. Aubrecht and D. Özceylan, "Identification of heat risk patterns in the U.S. National Capital Region by integrating heat stress and related vulnerability," Environment International, vol. 56, pp. 65-77, 2013.

[29] Q. Zhu, T. Liu, H. Lin et al., "The spatial distribution of health vulnerability to heat waves in Guangdong Province, China," Global Health Action, vol. 7, no. 1, p. 25051, 2014.

[30] L. Zeng, A. Woodward, Cirendunzhu, and Q. Liu, "Countylevel heat vulnerability of urban and rural residents in Tibet, China," Environmental Health, vol. 15, no. 1, 2016.

[31] S. L. Harlan, J. H. Declet-Barreto, W. L. Stefanov, and D. B. Petitti, "Neighborhood effects on heat deaths: social and environmental predictors of vulnerability in Maricopa County, Arizona," Environmental Health Perspectives, vol. 121, no. 2, pp. 197-204, 2013.

[32] L. Inostroza, M. Palme, and F. de la Barrera, "A heat vulnerability index: spatial patterns of exposure, sensitivity and adaptive capacity for Santiago de Chile," PLoS One, vol. 11, no. 9, Article ID e0162464, 2016.

[33] X. Guo, G. Huang, P. Jia, and J. Wu, "Estimating fine-scale heat vulnerability in Beijing through two approaches: spatial patterns, similarities, and divergence," Remote Sensing, vol. 11, no. 20, p. 2358, 2019.

[34] K. Hu, X. Yang, J. Zhong, F. Fei, and J. Qi, "Spatially explicit mapping of heat health risk utilizing environmental and socioeconomic data," Environmental Science \& Technology, vol. 51, no. 3, pp. 1498-1507, 2017.

[35] W. Dong, Z. Liu, L. Zhang, Q. Tang, H. Liao, and X. E. Li, "Assessing heat health risk for sustainability in Beijing's urban heat island," Sustainability, vol. 6, no. 10, pp. 7334-7357, 2014.

[36] Y. Ren, C. Y. Jim, J. Deng, and Z. Wang, "Urbanization effect on spatiotemporal thermal patterns and changes in Hangzhou (China)," Building and Environment, vol. 145, pp. 166-176, 2018.

[37] D. Zhou, S. Zhao, S. Liu, L. Zhang, and C. Zhu, "Surface urban heat island in China's 32 major cities: spatial patterns and drivers," Remote Sensing of Environment, vol. 152, pp. 51-61, 2014. 
[38] L. Sheng, D. Lu, and J. Huang, "Impacts of land-cover types on an urban heat island in Hangzhou, China," International Journal of Remote Sensing, vol. 36, no. 6, pp. 1584-1603, 2015.

[39] W. Yue and X. Liu, "Assessment on heat island effect based on urban regulatory planning," Chinese Journal of Applied Ecology, vol. 27, pp. 3631-3640, 2016.

[40] W. Yue, S. Qiu, H. Xu, L. Xu, and L. Zhang, "Polycentric urban development and urban thermal environment: a case of Hangzhou, China," Landscape and Urban Planning, vol. 189, pp. 58-70, 2019.

[41] T. Shen, D. Chow, and J. Darkwa, "Simulating the influence of microclimatic design on mitigating the urban heat island effect in the Hangzhou metropolitan area of China," International Journal of Low-Carbon Technologies, vol. 11, pp. 130-139, 2016.

[42] F. Chen, X. Yang, and W. Zhu, "WRF simulations of urban heat island under hot-weather synoptic conditions: the case study of Hangzhou City, China," Atmospheric Research, vol. 138, pp. 364-377, 2014.

[43] J. Tan, Y. Zheng, X. Tang et al., "The urban heat island and its impact on heat waves and human health in Shanghai," International Journal of Biometeorology, vol. 54, no. 1, pp. 75-84, 2010.

[44] D. P. Song, J. S. Wilson, and G. C. Luber, "Socioeconomic indicators of heat-related health risk supplemented with remotely sensed data," International Journal of Health Geographics, vol. 8, no. 1, p. 57, 2009.

[45] W. Luber, Y. Liu, and P. Fan, "Measuring urban sprawl and its drivers in large Chinese cities: the case of Hangzhou," Land Use Policy, vol. 31, pp. 358-370, 2013.

[46] Y. Liu, W. Yue, P. Fan, and Y. Song, "Suburban residential development in the era of market-oriented land reform: the case of Hangzhou, China," Land Use Policy, vol. 42, pp. 233-243, 2015.

[47] J. Zhao, J. Li, Q. Liu et al., "Leaf area index retrieval combining HJ1/CCD and Landsat8/OLI data in the Heihe River Basin, China," Remote Sensing, vol. 7, no. 6, pp. 6862-6885, 2015.

[48] X. Yang, X. Guo, and Z. Wu, "Land surface temperature retrieval from Landsat 8 TIRS-comparison between radiative transfer equation-based method, split window algorithm and single channel method," Remote Sensing, vol. 6, no. 10, pp. 9829-9852, 2014.

[49] D. Parastatidis, Z. Mitraka, N. Chrysoulakis, and M. Abrams, "Online global land surface temperature estimation from Landsat," Remote Sensing, vol. 9, no. 12, p. 1208, 2017.

[50] M. Ranagalage, Y. Murayama, D. Dissanayake, and M. Simwanda, "The impacts of landscape changes on annual mean land surface temperature in the tropical mountain city of Sri Lanka: a case study of Nuwara Eliya (1996-2017)," Sustainability, vol. 11, no. 19, pp. 5517-5542, 2019.

[51] D. Dissanayake, T. Morimoto, Y. Murayama, M. Ranagalage, and E. Perera, "Analysis of life quality in a tropical mountain city using a multi-criteria geospatial technique: a case study of Kandy City, Sri Lanka," Sustainability, vol. 12, no. 7, pp. 2918-2939, 2020.

[52] W. Yue, X. Liu, Y. Zhou, and Y. Liu, "Impacts of urban configuration on urban heat island: an empirical study in China mega-cities," Science of The Total Environment, vol. 671, pp. 1036-1046, 2019.

[53] A. Haines, R. Kovats, D. Campbell-Lendrum, and C. Corvalan, "Climate change and human health: impacts, vulnerability, and mitigation," The Lancet, vol. 367, no. 9528, pp. 2101-2109, 2006.
[54] J. Klein Rosenthal, P. L. Kinney, and K. B. Metzger, "Intraurban vulnerability to heat-related mortality in New York City, 1997-2006," Health \& Place, vol. 30, pp. 45-60, 2014.

[55] T. Benmarhnia, W. Kihal-Talantikite, M. S. Ragettli, and S. Deguen, "Small-area spatiotemporal analysis of heatwave impacts on elderly mortality in Paris: a cluster analysis approach," Science of The Total Environment, vol. 592, pp. 288-294, 2017.

[56] M. Medina-Ramón, A. Zanobetti, D. P. Cavanagh, and J. Schwartz, "Extreme temperatures and mortality: assessing effect modification by personal characteristics and specific cause of death in a multi-city case-only analysis," Environmental Health Perspectives, vol. 114, no. 9, pp. 1331-1336, 2006.

[57] M. Poumadère, C. Mays, S. Le Mer, and R. Blong, "The 2003 heat wave in France: dangerous climate change here and now," Risk Analysis, vol. 25, no. 6, pp. 1483-1494, 2005.

[58] X. Liu, Y. Zhou, W. Yue, X. Li, Y. Liu, and D. Lu, "Spatiotemporal patterns of summer urban heat island in Beijing, China using an improved land surface temperature," Journal of Cleaner Production, vol. 257, Article ID 120529, 2020.

[59] H. Shen, L. Huang, L. Zhang, P. Wu, and C. Zeng, "Long-term and fine-scale satellite monitoring of the urban heat island effect by the fusion of multi-temporal and multi-sensor remote sensed data: a 26-year case study of the city of Wuhan in China," Remote Sensing of Environment, vol. 172, pp. 109-125, 2016.

[60] A. A. van de Griend and M. Owe, "On the relationship between thermal emissivity and the normalized difference vegetation index for natural surfaces," International Journal of Remote Sensing, vol. 14, no. 6, pp. 1119-1131, 1993.

[61] E. Mallen, B. Stone, and K. Lanza, "A methodological assessment of extreme heat mortality modeling and heat vulnerability mapping in Dallas, Texas," Urban Climate, vol. 30, Article ID 100528, 2019.

[62] T. Wolf and G. McGregor, "The development of a heat wave vulnerability index for London, United Kingdom," Weather and Climate Extremes, vol. 1, pp. 59-68, 2013.

[63] A. M. Rizwan, L. Y. C. Dennis, and C. Liu, "A review on the generation, determination and mitigation of Urban Heat Island," Journal of Environmental Sciences, vol. 20, no. 1, pp. 120-128, 2008.

[64] Q. Weng, H. Liu, and D. Lu, "Assessing the effects of land use and land cover patterns on thermal conditions using landscape metrics in city of Indianapolis, United States," Urban Ecosystems, vol. 10, no. 2, pp. 203-219, 2007.

[65] R. Giridharan, S. S. Y. Lau, S. Ganesan, and B. Givoni, "Urban design factors influencing heat island intensity in high-rise high-density environments of Hong Kong," Building and Environment, vol. 42, no. 10, pp. 3669-3684, 2007.

[66] S. Peng, S. Piao, P. Ciais et al., "Surface urban heat island across 419 global big cities," Environmental Science \& Technology, vol. 46, no. 2, pp. 696-703, 2012.

[67] W. Nan, Y. Zhang, C. Peng, and W. Gao, "Evaluation of urbanization dynamics and its impacts on surface heat islands: a case study of Beijing, China," Remote Sensing, vol. 9, p. $453,2017$.

[68] S. Chen, D. Hu, M. S. Wong et al., "Characterizing spatiotemporal dynamics of anthropogenic heat fluxes: a 20 -year case study in Beijing-Tianjin-Hebei region in China," Environmental Pollution, vol. 249, pp. 923-931, 2019.

[69] L. Sheng, X. Tang, H. You, Q. Gu, and H. Hu, "Comparison of the urban heat island intensity quantified by using air 
temperature and Landsat land surface temperature in Hangzhou, China," Ecological Indicators, vol. 72, pp. 738-746, 2017.

[70] J. Yang, J. Sun, Q. Ge, and X. Li, “Assessing the impacts of urbanization-associated green space on urban land surface temperature: a case study of Dalian, China," Urban Forestry \& Urban Greening, vol. 22, pp. 1-10, 2017.

[71] K. M. A. Gabriel and W. R. Endlicher, "Urban and rural mortality rates during heat waves in Berlin and Brandenburg, Germany," Environmental Pollution, vol. 159, no. 8-9, pp. 2044-2050, 2011.

[72] K. Chen, J. McAneney, R. Blong, R. Leigh, L. Hunter, and C. Magill, "Defining area at risk and its effect in catastrophe loss estimation: a dasymetric mapping approach," Applied Geography, vol. 24, no. 2, pp. 97-117, 2004.

[73] S. B. Henderson, V. Wan, and T. Kosatsky, "Differences in heat-related mortality across four ecological regions with diverse urban, rural, and remote populations in British Columbia, Canada," Health \& Place, vol. 23, pp. 48-53, 2013.

[74] N. Debbage and J. M. Shepherd, "The urban heat island effect and city contiguity," Computers, Environment and Urban Systems, vol. 54, pp. 181-194, 2015. 